\title{
In vitro drug delivery performance of five valved holding chambers with and without facemasks
}

Péter Csonka ${ }^{1,2}, \mathrm{MD}, \mathrm{PhD}$ and Lauri Lehtimäki ${ }^{3,4}, \mathrm{MD}, \mathrm{PhD}$

Affiliations: ${ }^{1}$ Centre for Child Health Research, Tampere University and Tampere University Hospital, Tampere, Finland; ${ }^{2}$ Terveystalo Healthcare Oy, Tampere, Finland; ${ }^{3}$ Allergy Centre, Tampere University Hospital, Tampere, Finland; ${ }^{4}$ Faculty of Medicine and Health Technology, Tampere University, Tampere, Finland

Address correspondence to: Péter Csonka, Terveystalo Healthcare, Terveystalo Tampere, Rautatienkatu 27, 33100 Tampere, Finland. [peter.csonka@terveystalo.com], GSM: +358-50-3661103

Funding Source: This study was supported by the Foundation of the Finnish Anti-Tuberculosis Association, Research Foundation for Pulmonary Diseases, Tampere Tuberculosis Foundation, and Väinö and Laina Kivi Foundation.

Financial Disclosure: The authors have indicated they have no financial relationships relevant to this article to disclose.

Conflict of Interest: The other authors have indicated they have no potential conflicts of interest to disclose.

Abbreviations: CI, confidence interval; HPLC, high-performance liquid chromatography; LOD, limit of detection; LOQ, limit of quantitation; PIFR, peak inspiratory flow rate (governed by RR, $\mathrm{V}_{\mathrm{T}}$ and $t_{\mathrm{I}} / \mathrm{t}_{\mathrm{tot}}$ ); pMDI, pressurized metered dose inhaler; $R R$, respiratory rate; $t_{i} / t_{\text {tot }}$, inspiratory duty cycle (inspiratory proportion of the breathing cycle); $\mathrm{VHC}$, valved holding chamber; $\mathrm{V}_{\mathrm{T}}$, tidal volume.

Key words: salbutamol, spacer, inhalation administration, drug aerosol therapy, drug delivery performance

Short title: Drug delivery efficacy of five valved holding chambers 


\begin{abstract}
Background: Valved holding chambers (VHCs) are essential for efficient pulmonary delivery of inhaled medication in preschool children. The numerous devices on the market vary in material, aerodynamic characteristics, volume, valve properties, and mask design. Drug delivery is affected by the VHC characteristics as well as by the age and breathing pattern of the child.
\end{abstract}

Methods: We measured the drug delivery efficacy of five VHCs widely available on the market, evaluated the effect of facemasks; and tested the differences between manufacturing lots. A breathing simulator was used to mimic normal (respiratory rate (RR) 25/min and tidal volume ( $\mathrm{V}_{\mathrm{T}}$ ) $200 \mathrm{~mL}$ ) and obstructive (RR 50/min and $\mathrm{V}_{\mathrm{T}} 50 \mathrm{~mL}$ ) breathing of infants and toddlers.

Results: Salbutamol output was significantly higher with a normal breathing pattern compared to the obstructive breathing pattern in most VHCs. Without masks, the differences in the median in vitro filter doses of salbutamol were mainly from 2-10-fold among different types of VHCs. With masks, there was a greater than 20-fold difference in drug delivery capacity between the most and least effective devices. Most VHCs had a notable variation of performance between individual devices from different lots within the same brand.

Conclusions: There was an extreme variation in the salbutamol delivery performance among different types of VHCs for both normal and obstructive pediatric breathing patterns with and without masks. This magnitude of performance variability can have significant and unpredictable clinical implications. 


\section{Introduction}

Acute wheezing with bronchoconstriction is most common before school age compared to any other age group $^{1,2}$. Furthermore, acute exacerbations of asthma account for approximately $10 \%$ of emergency visits in children and result in hospitalization of $20-40 \%$ of $_{\text {cases }}{ }^{3}$. Efficient pulmonary delivery of aerosolized medication is particularly challenging in preschool children due to their variable respiratory rate (RR) and low tidal volume $\left(\mathrm{V}_{\mathrm{T}}\right)$.

The use of valved holding chambers (VHCs) improves drug delivery and precludes the need for the coordination of actuation-inhalation from a pressurized metered dose inhaler (pMDI) ${ }^{4,5}$. Facemasks (later referred to as masks) serve as a patient-device interface to facilitate drug delivery in children younger than four years and other patients who are incapable of holding a mouthpiece between the lips and teeth ${ }^{4}$. A tight, yet comfortable, mask-to-face seal is essential for reliable drug delivery ${ }^{6,7,8}$. Children from the age four years are generally able to use VHCs without masks ${ }^{4}$.

Commercially available VHCs and masks differ in material, electrostatic and aerodynamic characteristics; volume; dead space; valve properties; and mask design. The behavior of an aerosolized drug depends on the VHC and mask used. Certain combinations of pMDI-VHC may result in drastic differences in dose output $^{4,5,9,10,11,12,13}$.

Studies evaluating drug delivery by VHCs have mainly been performed with inspiratory flow rates of 20 $60 \mathrm{~L} / \mathrm{min}$, and only a few have used rates below $10 \mathrm{~L} / \mathrm{min}^{14,15,16}$. Nevertheless, drug delivery is dependent on the patient population since the breathing pattern, $\mathrm{V}_{\mathrm{T}}$, peak inspiratory flow rate (PIFR), and resting RR all change with growth and development ${ }^{13,17,18,19}$. Tidal volume is approximately $7-10 \mathrm{~mL} / \mathrm{kg}$ of ideal body weight ${ }^{19}$ in the first few years of life. With age, RR decreases while $\mathrm{V}_{\mathrm{T}}$ increases ${ }^{20}$. During bronchoconstriction, $\mathrm{V}_{\mathrm{T}}$ decreases and RR increases, and asthmatic patients have a higher range of 
variation in PIFR compared to healthy subjects ${ }^{18}$. Operation of VHCs under suboptimal conditions is clinically important since children below school age can have inspiratory flow rates as low as $2 \mathrm{~L} / \mathrm{min}^{18}$. A significant proportion of published studies evaluating and comparing the efficacy of VHCs are funded by their manufacturers, causing potential bias.

VHCs play a significant role in the treatment of millions of children worldwide. At present, there are no universal standards specifically applicable to orally inhaled drug products. Regional guidelines (e.g., by the European Medical Agency (EMA), US Food and Drug Administration (FDA), the Chinese Food and Drug Administration and the Japanese Ministry of Health, Labour and Welfare) provide a list of parameters that are critical to the safety, quality and efficacy of the final product depending on the specific type of inhaled preparation concerned. It has been recognized that the amount of drug received by the patient using an add-on device with pMDI will be directly influenced by the inhalation profile and user in question ${ }^{21}$.

To achieve a better understanding of how drug delivery is affected in different patient groups, test systems should reflect the physiology of the intended users, and the performance of a given pMDI should be tested with a particular VHC with and without masks ${ }^{22}$. The main goals of this study are to quantify the impact of VHCs in a clinically relevant way. When a mask is used, measurement of the emitted dose (ED) should be performed with an age specific face model that physiologically simulates accurate dimensions and facial tissue. In addition, the face model should be correctly aligned with the mask to mimic real life usage. An array of face models have been developed for this purpose, including the Sophia Anatomical Infant Nose-Throat (SAINT) model $^{23}$, the family of Aerosol Delivery to an Anatomical Model (ADAM) face models ${ }^{24}$, and the Soft Anatomical Mask (SAM) models ${ }^{25}$.

We recently reported marked differences in in vitro salbutamol delivery between two VHCs (Babyhaler, $\mathrm{BH}$ and Optichamber Diamond, OD) using numerous pediatric breathing patters ${ }^{13}$. Alarmingly, the drug 
delivery capacity of $\mathrm{BH}$, which is available on the market globally, was close to zero when measured with obstructive breathing patterns. There seems to be a risk for a very poor or unreliable drug delivery performance with some VHC models, especially in small children with bronchoconstriction (who have a very low $\mathrm{V}_{\mathrm{T}}$ and high $\mathrm{RR}$ ).

Our hypothesis was that the amount of salbutamol delivered through VHCs is affected by the design and material of the VHCs and their corresponding masks, causing significant differences between drug delivery efficacies among different available VHCs. We also hypothesized that the drug delivery efficacy may vary, even between individual VHCs of the same type. Therefore, the detailed aims of this study were: 1) to assess the drug delivery efficacy of five VHCs widely available on the market; 2) to evaluate the effect of masks; and 3) to test whether there are differences in drug delivery between individual devices of the same type from different manufacturing lots. As the breathing pattern has been shown to affect drug delivery ${ }^{13}$, we used two different breathing patterns that mimic the $\mathrm{RR}$ and $\mathrm{V}_{\mathrm{T}}$ of infants and small children during normal and obstructive breathing. 


\section{Materials and Methods}

\section{Device setup}

Delivery of salbutamol sulphate generated by a pMDI (Ventoline Evohaler $1 \mathrm{mg} / \mathrm{mL}$, GlaxoSmithKline Inc., Evreux, France) was measured in five types of VHCs with and without corresponding masks (table 1). The mask for each VHC was selected based on the manufacturers' recommendations. Three separate VHCs and masks from different manufacturing lots were used for each brand. Prior to each experiment, all the components of the VHCs were immersed in lukewarm water with detergent ${ }^{4}$ (Fairy Liquid, Proctor \& Gamble, UK), rinsed under running tap water, and left to air-dry vertically.

A previously validated horizontal test rig with a soft anatomical face model (SAM0) ${ }^{25}$ designed for the evaluation of VHC and mask performance was used (figure 1). Each VHC was positioned in its custom built cradle that could be fully adjusted to the optimal position. Each VHC-mask system was naturally applied against the face replica using a pulley system that delivered a constant force of $4.9 \mathrm{~N}^{26}$.

A filter (PARI Respiratory Equipment, Inc., USA) within a low dead-space (10 mL) filter holder was used to trap drug particles. For measurements without masks (figure 1A), the filter holder was positioned between the mouthpiece of the VHC and the breathing simulator (Sinus Breathing Simulator; PARI, Starnberg, Germany). When a mask was used, the filter holder was connected to an airtight metal tube inside the "mouth" of the face model (figure 1B). The location of the filter within SAM0 was chosen based on previous work ${ }^{8}$. The simulator produced alternating inspirations and expirations with a sinusoidal wave and a duty cycle (inspiratory proportion of the breathing cycle) of 0.5 . The accuracy of the breathing simulator was validated by a Fluke VT305 Gas Flow Analyzer (Fluke Biomedical, USA). 


\section{Measurement protocols}

We used two different clinically meaningful pediatric breathing patterns ${ }^{18}$ (table 2): RR 25/min with $\mathrm{V}_{\mathrm{T}}$ $200 \mathrm{~mL}$ (normal breathing) and RR 50/min with $\mathrm{V}_{\mathrm{T}} 50 \mathrm{~mL}$ (obstructive breathing) for each VHC and VHC-mask combination. For every setup, the salbutamol output was measured on six replications using individual devices from three lots.

Before each measurement sequence, pMDIs were primed by actuating them five times. Before every actuation, the pMDI was shaken vigorously five times. The pMDI was then inserted into the VHC and immediately actuated at the start of inhalation ${ }^{27}$. During each measurement, the valve movement was constantly assessed by visual inspection. Salbutamol was left to accumulate in the filter for eight breathing cycles, which has been shown to be sufficient to empty even larger volume $\mathrm{VHCs}^{4,26,27,28}$. The filters were sealed with Parafilm M (Bemis Company, Inc., Oshkosh, WI) until analysis of the drug content.

\section{Filter analysis}

Drug particles deposited on the filters in each measurement protocol were recovered and analyzed by high-performance liquid chromatography (HPLC) carried out by Emmace Consulting AB (Lund, Sweden). The HPLC method was based on the internal standard methodology, and the limit of quantitation (LOQ) was determined as the peak height corresponding to 10 times the noise level. The LOQ was $2 \mu \mathrm{g}$. The HPLC system (Agilent 1100) was fitted with the appropriate column (Symmetry [Waters], C18, $5 \mu \mathrm{m}, 50 \times 3.9 \mathrm{~mm})$. Bracketing standards were generated and run, and the accuracy of the standards was checked. The standards were injected and run at least 6 times. The percentage relative standard deviation of the bracketing standards was $<2 \%$ throughout the runs with excellent linearity $\left(y=0.0021 x, R^{2}=0.9998\right)$. To assess how the results were affected by the possible variation in the output of 
pMDIs, we measured the emitted dose of each pMDI used in the study six times by connecting a filter directly to the mouthpiece of the pMDI. The median dose of salbutamol sulphate measured directly from the mouthpiece of the pMDIs was close to the nominal dose, with only a minor variation overall (median $92.0 \mu \mathrm{g}, 95 \%$ confidence interval (CI) 90.0-94.1 $\mu \mathrm{g})$.

Statistics

On the basis of our previous study ${ }^{13}$, it was anticipated that six measurements for each device from each lot and 18 measurements for each VHC setup would allow the detection of possible significant differences. The data were not assumed to be normally distributed. The in vitro filter dose values are reported as the medians and minimum and maximum values. To test for pairwise differences in the in vitro filter dose values between different VHCs, setups and breathing patterns, the Mann-Whitney U test was used. To assess the difference between devices from three different lots, the Kruskal Wallis test was used. SPSS Statistics for Windows, version 24 (IBM Corp., Armonk, N.Y., USA) was used for data analysis. 


\section{Results}

Figure 2, table 3 and table 4 illustrate the drug delivery performances of three individual VHCs from different manufacturing lots for each of the five VHC types both with and without their corresponding masks.

\section{Effect of the VHC type}

When masks were not used, the difference in the delivered median dose was most conspicuous between Vortex and BH (15-fold) and less prominent between OD and Aerochamber Plus (AP) (not significant) (table 4). Without masks, AP, OD and Vortex were clearly superior to A2A and BH.

Effect of the mask

Drug delivery was significantly poorer with masks for each VHC type, except for OD. The performances of $\mathrm{A} 2 \mathrm{~A}, \mathrm{BH}$ and Vortex were extremely poor with masks, as drug delivery was reduced by $44-93 \%$ (table 3). Only AP and OD were noticeably superior to the others when masks were used. With masks, OD delivered a significantly higher dose of salbutamol compared to any other VHC for both breathing patterns. When masks were used, the difference in the median in vitro filter dose of salbutamol was over 20-fold, favoring OD over BH.

Between-lot variation

Most VHCs showed a notable variation of performance between individual devices from different lots. This between-lot variation was most prominent for $\mathrm{BH}$ and $\mathrm{A} 2 \mathrm{~A}$ (figure 2). 
Consistency of results using two different respiratory patterns

Salbutamol output was significantly higher with the normal breathing pattern (RR 25/min and $V_{T} 200$ $\mathrm{mL}$ ) compared to the obstructive breathing pattern (RR 50/min and $\mathrm{V}_{\mathrm{T}} 50 \mathrm{~mL}$ ) in all of the VHC models, except for BH without a mask and for Vortex with a mask (table 3). There were considerable differences in drug delivery between different VHC types for both respiratory patterns with and without masks (table 4). 


\section{Discussion}

We found an extreme variation in the in vitro drug delivery performances of five VHCs with or without mask and even between similar devices from different manufacturing lots. Additionally, drug delivery was most often decreased by the use of a facemask or when applying a shallow and rapid respiratory pattern related to an airway obstruction.

In line with previous studies ${ }^{14,29}$, we found that VHCs with a somewhat larger volume (i.e., A2A (210 $\mathrm{mL})$ and $\mathrm{BH}(350 \mathrm{~mL}))$ had a significantly lower salbutamol output at low $\mathrm{V}_{\mathrm{T}}$ compared to smaller volume VHCs. On the other hand, Vortex $(194 \mathrm{~mL})$ performed significantly better than A2A without masks, despite having a similar volume. It has been speculated that the aerosol concentration and particle impaction in a larger volume VHC are less than those in a smaller volume VHC, which results in lower inhaled doses at a small $\mathrm{V}_{\mathrm{T}}$ but higher doses when the VHC can be emptied faster with a larger $\mathrm{V}_{\mathrm{T}}{ }^{17,29}$. However, chamber volume is not the only factor that affects drug delivery ${ }^{11,24}$. For example, Vortex and A2A have comparable chamber volumes but differed in almost every other aspect (e.g., shape, material, and valve design), any of which could be responsible for the recovered drug mass on the filter.

We found that drug delivery was, in general, lower when a facemask was present using both respiratory patterns. This result is in line with findings from previous studies ${ }^{16}$. The lower drug delivery with masks and the variation between VHC-mask systems can be explained by the considerable differences in mask shape, volume and flexibility. The dead space and leak of the VHC-mask system have important implications. With the relatively large mask dead space $(80 \mathrm{~mL})$ of $\mathrm{BH}$ and its large chamber volume,

only minimal amounts of drug would be delivered to the respiratory tract of infants with a low $\mathrm{VT}^{29}$. $\mathrm{A} 2 \mathrm{~A}$ has a similar mask dead space compared to $\mathrm{BH}$, but its lower chamber volume could possibly explain its 
higher drug output compared to BH. On the other hand, the filter dose of salbutamol was much lower using Vortex with a facemask present than without it. Since the dead space of this mask is relatively low, leakage of air between mask and the face model could explain the low amount of drug recovered from the filter ${ }^{6,30,31}$.

The degree of adaptability and flexibility of the mask are also important factors that influence the fit and mask-to-face seal as well as the physical dead space of the mask ${ }^{32}$. When pressed against the face, pressure causes compression of the mask, tightening the contact and reducing the actual mask dead space $^{33,34}$. Thus, drug delivery will be affected by the force applied by the caregiver as well as the flexibility, compressibility and shape of the mask. A good seal with a minimal leak around the nose, cheeks, and mouth will ensure inspiration through the VHC and not allow ingress of ambient air between the mask and face ${ }^{6,7}$.

Minh et al. ${ }^{26}$ investigated how children and their caregivers react to mask application force in $1-4$ yearold children. They found that the mask was best accepted when the mean mask application force was approximately $4 \mathrm{~N}$. When the pressure against the face increases, children become agitated and a tight seal is difficult to maintain. With increasing discomfort, children are more likely to cry or scream, which also decreases the inhaled dose $\mathrm{e}^{31,35}$. Shah et al. ${ }^{33}$ tested seven commonly used masks with various applied forces. Mask leakage was properly eliminated at a $6.7 \mathrm{~N}$ applied force, with only two out of the seven masks investigated, meaning that most masks require a higher application force, which will not always be accepted by children. Esposito-Festen et al. ${ }^{36}$ found that the lung dose decreased more rapidly when the mask leak was located close to the nose relative to a leak situated near the chin. Depending on the location and size of the mask leak, drug delivery can be very low, close to the limit of detection. In our 
study, the mask fit to the anatomical face model considerably varied. We did not measure the degree of mask leak, but by visual inspection, the best seal appears to have been achieved by the OD mask.

We are not aware of other studies reporting the between-lot variability of VHCs. Although we did not evaluate valve function, mechanical anomalies might explain our finding. Valves are fine structures in which even small inequalities may considerably affect their function especially at a low respiratory flow. Unfortunately, little is known about the minimum required flow rates needed by VHCs and VHC-mask systems to operate properly ${ }^{37}$.

In most VHC models under investigation, a normal breathing pattern yielded a higher output dose compared to an obstructive breathing pattern. Drug delivery through VHCs has been shown to be dependent on the inhalation volume and flow ${ }^{13,32,38,39,40}$. Chavez and colleagues ${ }^{16}$ found that gradually increasing the $\mathrm{V}_{\text {T }}$ from $36 \mathrm{~mL}$ to $290 \mathrm{~mL}$ led the filter dose of albuterol to increase in a logarithmic fashion with RRs of $12 \mathrm{~L} / \mathrm{min}$ and $24 \mathrm{~L} / \mathrm{min}$, respectively. Similarly to our findings, Mitchell et al. ${ }^{10}$ reported that some VHC designs yielded undetectable levels of salbutamol in challenging circumstances (RR 30/min with VT $50 \mathrm{~mL}$ ).

Our results are limited to the in vitro model used to compare the drug delivery efficacy of VHCs and masks. As we did not use an anatomical model of the airways or a cascade impactor but measured drug deposition right behind the oral cavity of the face model, we are over-estimating true pulmonary drug deposition and direct conclusions on pulmonary drug deposition in vivo cannot be made. However, the advantages of using an in vitro setting are the possibility to make multiple repeated measures and to avoid patient related sources of error, which allows the properties of the devices themselves to be focused on. In 
addition, different predefined respiratory patterns can be tested in a repeatable manner between different device types. Further, our results only apply to the two breathing patterns tested. These quite reliably reflect $\mathrm{V}_{\mathrm{T}}$ and $\mathrm{RR}$ during normal and obstructive breathing in children between one and six years of age, but the VHCs might perform better in older children with a higher $\mathrm{V}_{\text {т. }}$ In some children, application of a mask might result in irregular breathing with a sudden decrease or increase in inspiratory flow. Under experimental conditions, it is not possible to study all the potential combinations of breathing patterns. Certain breathing patterns are not present in the same child or in the same age group because masks are mainly used in children below 3-4 years of age. Nevertheless, the measured differences are consistent and the main conclusions remain the same.

We used a respiratory simulator that produced a regular sinusoidal respiratory cycle instead of a random variable natural pattern in real subjects. Due to the sinusoidal pattern of respiratory cycle in our simulator, the duty cycle (proportion of inspiratory time of the whole respiratory cycle) was 0.5 . This is not typical to humans and in young children duty cycle may be as low as 0.25 . Therefore, although $\mathrm{V}_{\mathrm{T}}$ and $\mathrm{RR}$ in our study were comparable to real-life settings, the peak inspiratory flow differs from real breathing cycles in which the inspiratory proportion and curve shape differ from the experimental sinusoidal pattern.

Although there were drastic differences in total drug delivery through the different types of VHCs, this may not reflect equal differences in actual pulmonary deposition in vivo. The in vitro filter dose represents the total dose of delivered drug particles regardless of their size. Pulmonary deposition and the clinical effect are influenced not only by the total dose but also by the particle size distribution of the aerosol delivered through the VHC. 
In conclusion, there is a marked difference in in vitro drug delivery between different types of VHCs and their masks in normal and obstructive pediatric breathing patterns. Therefore, these devices cannot be regarded as interchangeable, and the recommended drug doses should be based on the properties of each VHC. Clinical trials are needed to test whether these differences in in vitro drug delivery also cause differences in treatment responses in vivo. 


\section{Acknowledgements}

The test rig was borrowed form Philips Respironics, Tangmere, UK and the respiratory simulator was borrowed from Children's Hospital Falun, Dalarna, Sweden. We would like to thank Mikael Csonka for his practical help. 


\section{References}

1. Kuehni CE, Davis A, Brooke AM, Silverman M. Are all wheezing disorders in very young (preschool) children increasing in prevalence? Lancet. 2001;357(9271):1821-1825. doi:10.1016/S01406736(00)04958-8

2. Jurca M, Pescatore AM, Goutaki M, Spycher BD, Beardsmore CS, Kuehni CE. Age-related changes in childhood wheezing characteristics: A whole population study. Pediatric Pulmonology. 2017;52(10):1250-1259. doi:10.1002/ppul.23783

3. Csonka P, Mertsola J, Klaukka T, Kaila M, Ståhlberg MR, Ashorn P. Corticosteroid therapy and need for hospital care in wheezing preschool children. European Journal of Clinical Pharmacology. 2000;56(8):591-596. doi:10.1007/s002280000199

4. Global Strategy for Asthma Management and Prevention - updated 2018. doi:10.1183/09031936.00138707

5. Amirav I, Newhouse MT. Review of optimal characteristics of face-masks for Valved-Holding Chambers (VHCs). Pediatric Pulmonology. 2008;43(3):268-274. doi:10.1002/ppul.20767

6. Amirav I, Newhouse M. Aerosol therapy with valved holding chambers in young children: importance of the facemask seal. Pediatrics. 2001;108(2):389-394. doi:10.1542/peds.108.2.389

7. Janssens HM, Tiddens HAWM. Facemasks and Aerosol Delivery by Metered Dose Inhaler-Valved Holding Chamber in Young Children: A Tight Seal Makes the Difference. Journal of Aerosol Medicine. 2007;20(s1):S59-S65. doi:10.1089/jam.2007.0578

8. Nikander K, Berg E, Smaldone GC. Jet Nebulizers versus Pressurized Metered Dose Inhalers with Valved Holding Chambers: Effects of The Facemask on Aerosol Delivery. Journal of Aerosol Medicine. 2007;20(s1):S46-S58. doi:10.1089/jam.2007.0588

9. Barry PW, O'Callaghan C. In vitro comparison of the amount of salbutamol available for inhalation from different formulations used with different spacer devices. European Respiratory Journal. 1997;10(6):1345-1348. doi:10.1183/09031936.97.10061345 
10. Mitchell JP, Nagel MMWMM. In Vitro Performance Testing of Three Small Volume-Holding Chambers under Conditions That Correspond with Use by Infants and Small Children. Journal of Aerosol Medicine. 1997;10(4):341-349. doi:10.1089/jam.1997.10.341

11. Berg E, Madsen J, Bisgaard H. In vitro performance of three combinations of spacers and pressurized metered dose inhalers for treatment in children. European Respiratory Journal. 1998;12(2):472-476. doi:10.1183/09031936.98.12020472

12. Janssens HM, Heijnen EMEW, De Jong VM, Hop WCJ, Holland WPJ, De Jongste JC, Tiddens HAWM. Aerosol delivery from spacers in wheezy infants: A daily life study. European Respiratory Journal. 2000;16(5):850-856. doi:10.1088/0953-8984/1/25/010

13. Csonka P, Lehtimäki L. Valved holding chamber drug delivery is dependent on breathing pattern and device design. ERJ Open Research. 2019;5(1):00158-02018. doi:10.3390/rs6109653

14. Schultz A, Le Souëf TJ, Looi K, Zhang G, Le Souëf PN, Devadason SG. Validation of methodology for recording breathing and simulating drug delivery through spacers and valved holding chambers. Journal of aerosol medicine and pulmonary drug delivery. 2010;23(5):311-322. doi:10.1089/jamp.2008.0733

15. Slator L, von Hollen D, Sandell D, Hatley RHM. In Vitro Comparison of the Effect of Inhalation Delay and Flow Rate on the Emitted Dose from Three Valved Holding Chambers. Journal of Aerosol Medicine and Pulmonary Drug Delivery. 2014;27(S1):S-37-S-43. doi:10.1089/jamp.2013.1061

16. Chavez A, McCracken A, Berlinski A. Effect of face mask dead volume, respiratory rate, and tidal volume on inhaled albuterol delivery. Pediatric Pulmonology. 2010;45(3):224-229. doi:10.1002/ppul.21156

17. Vincken W, Levy ML, Scullion J, Usmani OS, Dekhuijzen PNR, Corrigan CJ. Spacer devices for inhaled therapy: why use them, and how? ERJ Open Research. 2018;4(2):1-10. doi:10.1183/23120541.00065-2018

18. Nikander K, Denyer J. Breathing patterns. European Respiratory Review. 2000;10(76):576-579. 19. Rubin BK, Mba M, Fink JB, Faarc RRT, Comfort FM. Optimizing Aerosol Delivery by Pressurized 
Metered-Dose Inhalers. Respiratory Care. 2005;50(9):1191-1200. doi:10.1088/1361-6668/aa8e28

20. Fleming S, Thompson M, Stevens R, Heneghan C, Plüddemann A, Maconochie I, Tarassenko L, Mant D. Normal Ranges of Heart Rate and Respiratory Rate in Children from Birth to 18 Years of Age Supplementa. The Lancet. 2011;6736(10):1011-1018. doi:10.1016/S0140-6736(10)62226-X.Normal 21. Dolovich MB, Mitchell JP. Canadian Standards Association standard CAN/CSA/Z264.1-02:2002: A new voluntary standard for spacers and holding chambers used with pressurized metered-dose inhalers. Canadian Respiratory Journal. 2004;11(7):489-495. doi:10.1155/2004/497946

22. USP Chapter $<1602>$ Spacers and Valved Holding Chambers Used with Inhalation Aerosols Characterization Tests. 2018.

23. Janssens HM, de Jongste JC, Fokkens WJ, Robben SGF, Wouters K, Tiddens HAWM. The Sophia Anatomical Infant Nose-Throat (Saint) Model: A Valuable Tool to Study Aerosol Deposition in Infants. Journal of Aerosol Medicine. 2002;14(4):433-441. doi:10.1089/08942680152744640

24. Mitchell JP, Dolovich MMB. Clinically Relevant Test Methods to Establish In Vitro Equivalence for Spacers and Valved Holding Chambers Used with Pressurized Metered Dose Inhalers (pMDIs). Journal of Aerosol Medicine and Pulmonary Drug Delivery. 2012;25(4):217-242. doi:10.1089/jamp.2011.0933 25. Xu Z, Hsu W, von Hollen D, Viswanath A, Nikander K, Dalby R. Methodology for the In Vitro Evaluation of the Delivery Efficiency from Valved Holding Chambers with Facemasks. Journal of Aerosol Medicine and Pulmonary Drug Delivery. 2014;27(S1):S-44-S-54. doi:10.1089/jamp.2013.1074 26. Minh KT, von Hollen D, von Königslöw AJ, Nikander K, Janssens HM. An Instrumented Valved Holding Chamber with Facemask to Measure Application Forces and Flow in Young Asthmatic Children. Journal of Aerosol Medicine and Pulmonary Drug Delivery. 2014;27(S1):S-55-S-62. doi:10.1089/jamp.2014.1129

27. Berlinski A, von Hollen D, Hatley RHM, Hardaker LEA, Nikander K. Drug Delivery in Asthmatic Children Following Coordinated and Uncoordinated Inhalation Maneuvers: A Randomized Crossover Trial. Journal of Aerosol Medicine and Pulmonary Drug Delivery. 2017;30(3):182-189. doi:10.1089/jamp.2016.1337 
28. Schultz A, Le Souef TJ, Venter A, Zhang G, Devadason SG, Le Souef PN. Aerosol Inhalation From Spacers and Valved Holding Chambers Requires Few Tidal Breaths for Children. Pediatrics. 2010;126(6):e1493-e1498. doi:10.1542/peds.2010-1377

29. Turpeinen M, Nikander K, Malmberg LP, Pelkonen AS, Turpeinen M, Nikander K, Malmberg LP PA. Metered Dose Inhaler Add-On Devices: Is the Inhaled Mass of Drug Dependent on the Size of the Infant? Journal of Aerosol Medicine. 1999;12(3):171-176. doi:10.1089/jam.1999.12.171

30. Ditcham W, Murdzoska J, Zhang G, Roller C, von Hollen D, Nikander K, Devadason SG. Lung Deposition of ${ }^{99 \mathrm{~m}}$ Tc-Radiolabeled Albuterol Delivered through a Pressurized Metered Dose Inhaler and Spacer with Facemask or Mouthpiece in Children with Asthma. Journal of Aerosol Medicine and Pulmonary Drug Delivery. 2014;27(S1):S-63-S-75. doi:10.1089/jamp.2014.1139

31. Erzinger S, Schueepp KG, Brooks-Wildhaber J, Devadason SG, Wildhaber JH. Facemasks and Aerosol Delivery In Vivo. Journal of Aerosol Medicine. 2007;20(s1):S78-S84. doi:10.1089/jam.2007.0572

32. Janssens HM, Krijgsman A, Verbraak TFM, Hop WCJ, de Jongste JC, Tiddens HAWM. Determining Factors of Aerosol Deposition for Four pMDI-Spacer Combinations in an Infant Upper Airway Model. Journal of Aerosol Medicine. 2004;17(1):51-61. doi:10.1089/089426804322994460

33. Shah SA, Berlinski AB RB. Force-dependent static dead space of face masks used with holding chambers. Respiratory Care. 2006;51:140-144.

34. Amirav I, Luder AS, Halamish A, Marzuk C, Daitzchman M, Newhouse MT. Computerized DeadSpace Volume Measurement of Face Masks Applied to Simulated Faces. Respiratory Care. 2015;60(9):1247-1251. doi:10.4187/respcare.03813

35. Iles R, Lister P, Edmunds AT. Crying significantly reduces absorption of aerosolised drug in infants. Archives of Disease in Childhood. 1999;81(2):163-165. doi:10.1136/adc.81.2.163

36. Esposito-Festen JEE, Ates B, van Vliet FJMJM, Verbraak AFMFM, de Jongste JCC, Tiddens HAWMAWM. Effect of a facemask leak on aerosol delivery from a pMDI-spacer system. Journal of aerosol medicine : the official journal of the International Society for Aerosols in Medicine. 
2004;17(1):1-6. doi:10.1089/089426804322994406

37. Haidl P, Heindl S, Siemon K, Bernacka M, Cloes RM. Inhalation device requirements for patients' inhalation maneuvers. Respiratory Medicine. 2016;118:65-75. doi:10.1016/j.rmed.2016.07.013 38. Piérart F, Wildhaber JH, Vrancken I, Devadason SG, Le Souëf PN. Washing plastic spacers in household detergent reduces electrostatic charge and greatly improves delivery. European Respiratory Journal. 1999;13(3):673-678. doi:10.1183/09031936.99.13367399

39. Barry PW, O'Callaghan C. The output of budesonide from spacer devices assessed under simulated breathing conditions. Journal of Allergy and Clinical Immunology. 1999;104(6):1205-1210. doi:10.1016/S0091-6749(99)70014-X

40. Everard ML, Clark AR, Milner AD. Drug delivery from holding chambers with attached facemask. Archives of Disease in Childhood. 1992;67(5):580-585. doi:10.1136/adc.67.5.580 

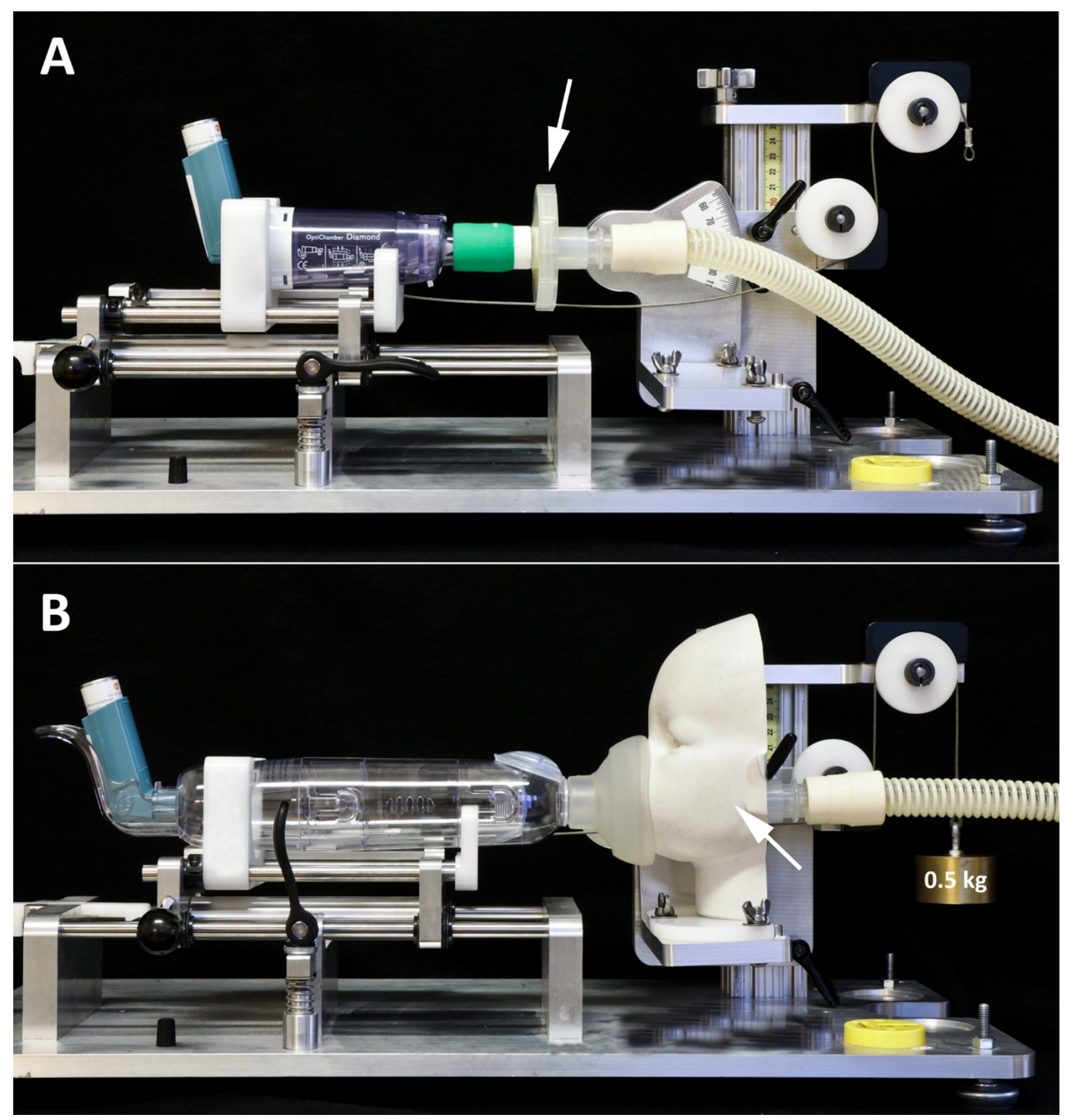

Figure 1. Setup to test drug delivery through different types of valved holding chambers (VHC) without face mask (A) and with face mask (B). To collect delivered salbutamol the filter (arrow) was placed between the VHC mouth piece and tubing to the breathing simulator when face mask was not used (A). When face mask was used, the filter (arrow) was placed behind the oral cavity of the anatomical face model (B) and the face mask was gently pressed against the face model by a pulley system creating a force of $4.9 \mathrm{~N}$. 

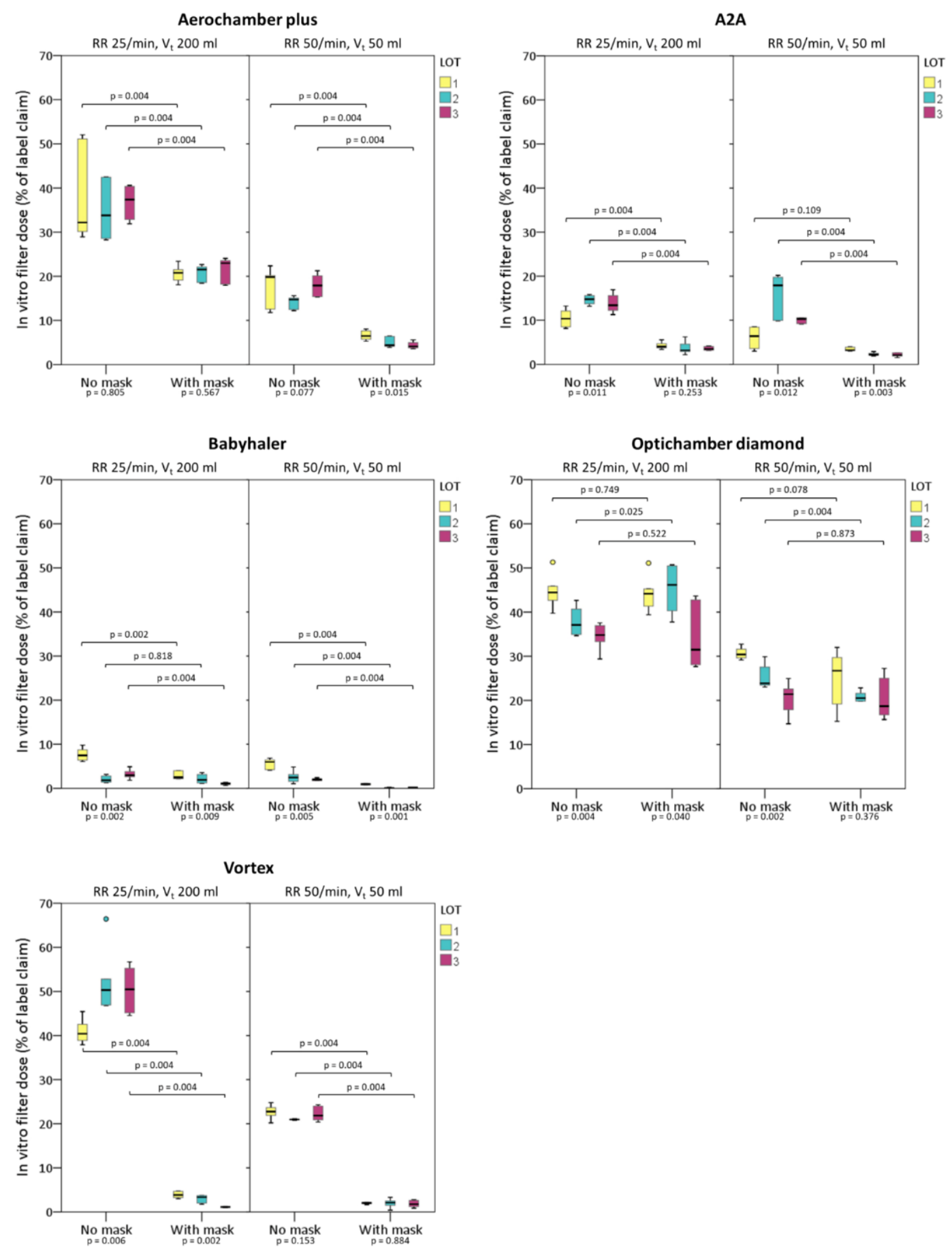

Figure 2. Drug delivery performance of five different types of valved holding chambers (VHC) with and without corresponding face masks. For each type of VHC, three individual devices from different manufacturing lots were used. Each box-plot represents six measurements using an individual device (middle thick line, median; box area, 25-75th percentiles; upper and lower whiskers, minimum and maximum values; round dots, outliers). P-values above bars are for the difference between "no mask" and "with mask" for each individual device, Mann-Whitney U test. P-values below groups of "no mask" and "with mask" are for the difference between lots within the group, Kruskal Wallis test. RR, respiratory rate. Vt, tidal volume. lot, manufacturing lot. 
Table 1. Characteristics of the valved holding chambers

\begin{tabular}{|c|c|c|c|c|}
\hline & VHC volume & $\begin{array}{l}\text { Chamber material } \\
\text { and static charge }{ }^{a}\end{array}$ & Valve characteristics and additional features & $\begin{array}{l}\text { Facemask } \\
\text { volume }^{\text {b }}\end{array}$ \\
\hline A2A Spacer (A2A) & $210 \mathrm{~mL}$ & plastic, antistatic & $\begin{array}{l}\text { Internal circular unidirectional silicon valve, aerosol pass } \\
\text { through the valve centrally }\end{array}$ & $80 \mathrm{~mL}$ \\
\hline Aerochamber plus (AP) & $149 \mathrm{~mL}$ & plastic, antistatic & $\begin{array}{l}\text { Internal circular unidirectional silicon valve, aerosol pass } \\
\text { at the valve periphery, top outside inspiratory indicator }\end{array}$ & $46 \mathrm{~mL}$ \\
\hline Babyhaler (BH) & $350 \mathrm{~mL}$ & plastic, non-electrostatic & $\begin{array}{l}\text { Internal circular unidirectional silicon valve hinged } \\
\text { centrally, aerosol pass at the valve periphery, additional } \\
\text { top outside valve }\end{array}$ & $80 \mathrm{~mL}$ \\
\hline Optichamber diamond (OD) & $140 \mathrm{~mL}$ & plastic, antistatic & $\begin{array}{l}\text { Internal cone shaped unidirectional silicon valve, aerosol } \\
\text { pass through the valve centrally, additional top outside } \\
\text { expiratory valve }\end{array}$ & $45 \mathrm{~mL}$ \\
\hline Vortex & $194 \mathrm{~mL}$ & metal, reduced static charge & $\begin{array}{l}\text { Internal cone shaped unidirectional silicon valve, aerosol } \\
\text { pass through the valve centrally }\end{array}$ & $46 \mathrm{~mL}$ \\
\hline
\end{tabular}

\section{aSpecified by the manufacturer}

${ }^{b}$ Mask volume of the smallest available mask of each valved holding chamber (VHC). Measured by water displacement technique. 
Table 2. Breathing patterns used and corresponding mean and peak inspiratory flows.

\begin{tabular}{lccccc} 
& $\begin{array}{c}\text { Respiratory } \\
\text { rate }\end{array}$ & $\begin{array}{c}\text { Tidal } \\
\text { volume }\end{array}$ & $\begin{array}{c}\text { Minute ventilation } \\
\text { (L/min) }\end{array}$ & $\begin{array}{c}\text { Mean inspiratory } \\
\text { flow (L/min) }\end{array}$ & $\begin{array}{c}\text { Peak inspiratory } \\
\text { flow (L/min) }\end{array}$ \\
\hline $\begin{array}{l}\text { Normal breathing } \\
\begin{array}{l}\text { Obstructive } \\
\text { breathing }\end{array}\end{array}$ & $25 / \mathrm{min}$ & $200 \mathrm{ml}$ & 5.0 & 10.0 & 15.7 \\
\hline
\end{tabular}


Table 3. Pairwise comparison of drug delivery between two types of breathing patterns for the same valved holding chambers brand. Results for each device type and setting represent 18 measurements pooled from six measurements on each three individual devices from three different lots. In vitro filter dose of salbutamol $(\mu \mathrm{g})$ expressed as median ( $95 \%$ confidence interval, $\mathrm{Cl}$ ), RR $25 / \mathrm{min}$ with $\mathrm{V}_{\mathrm{T}} 200 \mathrm{ml}$ represents normal breathing while $\mathrm{RR} 50 / \mathrm{min}$ with $\mathrm{V}_{\mathrm{T}} 50 \mathrm{ml}$ represents obstructive breathing.

\begin{tabular}{|c|c|c|c|c|c|}
\hline & \multirow{2}{*}{\multicolumn{2}{|c|}{ No mask }} & & & \\
\hline & & & \multicolumn{2}{|l|}{ With mask } & \multirow{2}{*}{$\begin{array}{l}\text { Change in drug delivery } \\
\text { when mask is used }\end{array}$} \\
\hline & Median $(95 \% \mathrm{Cl}) \mu \mathrm{g}$ & P-value & Median $(95 \% \mathrm{Cl}) \mu \mathrm{g}$ & P-value & \\
\hline A2A Spacer, normal breathing & $13.2(11.3-15.3)$ & \multirow{2}{*}{0.040} & $3.8(3.2-4.2)$ & \multirow{2}{*}{$<0.001$} & $-71.2 \%$ \\
\hline A2A Spacer, obstructive breathing & $10.0(8.5-10.6)$ & & $2.6(2.1-3.1)^{\mathrm{a}}$ & & $-74.0 \%$ \\
\hline Aerochamber, normal breathing & $33.8(31.8-40.6)$ & \multirow{2}{*}{$<0.001$} & $21.5(18.6-22.7)$ & \multirow{2}{*}{$<0.001$} & $-36.4 \%$ \\
\hline Aerochamber, obstructive breathing & $15.5(14.5-20.1)$ & & $5.2(4.2-6.4)$ & & $-66.5 \%$ \\
\hline Babyhaler, normal breathing & $3.2(2.1-6.4)^{\mathrm{a}}$ & \multirow{2}{*}{0.367} & $1.8(1.2-2.5)^{a}$ & \multirow{2}{*}{$<0.001$} & $-43.8 \%$ \\
\hline Babyhaler, obstructive breathing & $2.6(2.0-4.9)^{\mathrm{a}}$ & & $0.2(0.1-0.8)^{\mathrm{a}}$ & & $-92.3 \%$ \\
\hline Optichamber, normal breathing & $37.5(35.0-42.7)$ & \multirow{2}{*}{$<0.001$} & $43.0(37.8-45.3)$ & \multirow{2}{*}{$<0.001$} & $+14.7 \%$ \\
\hline Optichamber, obstructive breathing & $24.6(22.6-29.9)$ & & $20.5(19.2-25.7)$ & & $-16.7 \%$ \\
\hline Vortex, normal breathing & $46.9(42.6-51.0)$ & \multirow{2}{*}{$<0.001$} & $3.1(1.2-3.8)^{a}$ & \multirow{2}{*}{0.150} & $-93.4 \%$ \\
\hline Vortex, obstructive breathing & $21.1(20.9-23.0)$ & & $2.0(1.6-2.3)^{\mathrm{a}}$ & & $-90.5 \%$ \\
\hline
\end{tabular}

Values in bold $=$ VHC with statistically significantly higher drug delivery in the pairwise comparison.

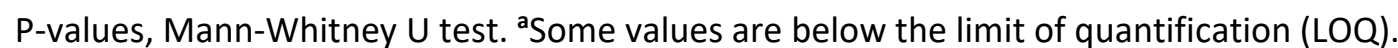


Table 4. Pairwise comparison of drug delivery between different types of valved holding chambers. Results for each device type and setting represent 18 measurements pooled from six measurements on all three individual devices from three different lots. In vitro filter dose of salbutamol ( $\mu \mathrm{g})$ expressed as median (95\% confidence interval, $\mathrm{Cl}$ ).

\begin{tabular}{|c|c|c|c|c|c|c|c|c|}
\hline & \multicolumn{4}{|c|}{ Normal breathing (RR 25/min, $\mathrm{V}_{\mathrm{T}} 200 \mathrm{ml}$ ) } & \multicolumn{4}{|c|}{ Obstructive breathing (RR 50/min, $V_{T} 50 \mathrm{ml}$ ) } \\
\hline & \multicolumn{2}{|c|}{ No mask } & \multicolumn{2}{|c|}{ With mask } & \multicolumn{2}{|c|}{ No mask } & \multicolumn{2}{|c|}{ With mask } \\
\hline & $\begin{array}{l}\text { Median } \\
(95 \% \mathrm{Cl}) \mu \mathrm{g}\end{array}$ & P-value & $\begin{array}{l}\text { Median } \\
(95 \% \mathrm{Cl}) \mu \mathrm{g}\end{array}$ & P-value & $\begin{array}{l}\text { Median } \\
(95 \% \mathrm{Cl}) \mu \mathrm{g}\end{array}$ & P-value & $\begin{array}{l}\text { Median } \\
(95 \% \mathrm{Cl}) \mu \mathrm{g}\end{array}$ & P-value \\
\hline $\begin{array}{l}\text { A2A Spacer } \\
\text { Aerochamber plus }\end{array}$ & $\begin{array}{l}13.2(11.3-15.3) \\
\mathbf{3 3 . 8}(\mathbf{3 1 . 8}-\mathbf{4 0 . 6 )}\end{array}$ & $<0.001$ & $\begin{array}{l}3.8(3.2-4.2) \\
21.5(18.6-22.7)\end{array}$ & $<0.001$ & $\begin{array}{l}10.0(8.5-10.6) \\
\mathbf{1 5 . 5}(\mathbf{1 4 . 5 - 2 0 . 1 )}\end{array}$ & $<0.001$ & $\begin{array}{l}2.6(2.1-3.1)^{a} \\
5.2(4.2-6.4)\end{array}$ & $<0.001$ \\
\hline $\begin{array}{l}\text { A2A Spacer } \\
\text { Babyhaler }\end{array}$ & $\begin{array}{l}13.2(11.3-15.3) \\
3.2(2.1-6.4)^{\mathrm{a}}\end{array}$ & $<0.001$ & $\begin{array}{l}3.8(3.2-4.2) \\
1.8(1.2-2.5)^{\mathrm{a}}\end{array}$ & $<0.001$ & $\begin{array}{l}10.0(8.5-10.6) \\
2.6(2.0-4.9)^{\mathrm{a}}\end{array}$ & $<0.001$ & $\begin{array}{l}2.6(2.1-3.1)^{a} \\
0.2(0.1-0.8)^{a}\end{array}$ & $<0.001$ \\
\hline $\begin{array}{l}\text { A2A Spacer } \\
\text { Optichamber diamond }\end{array}$ & $\begin{array}{l}13.2(11.3-15.3) \\
\mathbf{3 7 . 5}(\mathbf{3 5 . 0 - 4 2 . 7 )}\end{array}$ & $<0.001$ & $\begin{array}{l}3.8(3.2-4.2) \\
43.0(37.8-45.3)\end{array}$ & $<0.001$ & $\begin{array}{l}10.0(8.5-10.6) \\
24.6(22.6-29.9)\end{array}$ & $<0.001$ & $\begin{array}{l}2.6(2.1-3.1)^{\mathrm{a}} \\
20.5(19.2-25.7)\end{array}$ & $<0.001$ \\
\hline $\begin{array}{l}\text { A2A Spacer } \\
\text { Vortex }\end{array}$ & $\begin{array}{l}13.2(11.3-15.3) \\
46.9(42.6-51.0)\end{array}$ & $<0.001$ & $\begin{array}{l}3.8(3.2-4.2) \\
3.1(1.2-3.8)^{a}\end{array}$ & 0.018 & $\begin{array}{l}10.0(8.5-10.6) \\
21.1(20.9-23.0)\end{array}$ & $<0.001$ & $\begin{array}{l}2.6(2.1-3.1) \\
2.0(1.6-2.3)^{a}\end{array}$ & 0.012 \\
\hline $\begin{array}{l}\text { Aerochamber plus } \\
\text { Babyhaler }\end{array}$ & $\begin{array}{l}33.8(31.8-40.6) \\
3.2(2.1-6.4)^{\mathrm{a}}\end{array}$ & $<0.001$ & $\begin{array}{l}21.5(\mathbf{1 8 . 6 - 2 2 . 7 )} \\
1.8(1.2-2.5)^{\mathrm{a}}\end{array}$ & $<0.001$ & $\begin{array}{l}15.5(14.5-20.1) \\
2.6(2.0-4.9)^{a}\end{array}$ & $<0.001$ & $\begin{array}{l}5.2(4.2-6.4) \\
0.2(0.1-0.8)^{a}\end{array}$ & $<0.001$ \\
\hline $\begin{array}{l}\text { Aerochamber plus } \\
\text { Optichamber diamond }\end{array}$ & $\begin{array}{l}33.8(31.8-40.6) \\
37.5(35.0-42.7)\end{array}$ & 0.076 & $\begin{array}{l}21.5(18.6-22.7) \\
43.0(37.8-45.3)\end{array}$ & $<0.001$ & $\begin{array}{l}15.5(14.5-20.1) \\
24.6(22.6-29.9)\end{array}$ & $<0.001$ & $\begin{array}{l}5.2(4.2-6.4) \\
20.5(19.2-25.7)\end{array}$ & $<0.001$ \\
\hline $\begin{array}{l}\text { Aerochamber plus } \\
\text { Vortex }\end{array}$ & $\begin{array}{l}33.8(31.8-40.6) \\
46.9(42.6-51.0)\end{array}$ & $<0.001$ & $\begin{array}{l}21.5(18.6-22.7) \\
3.1(1.2-3.8)^{a}\end{array}$ & $<0.001$ & $\begin{array}{l}15.5(14.5-20.1) \\
21.1(20.9-23.0)\end{array}$ & $<0.001$ & $\begin{array}{l}5.2(4.2-6.4) \\
2.0(1.6-2.3)^{a}\end{array}$ & $<0.001$ \\
\hline $\begin{array}{l}\text { Babyhaler } \\
\text { Optichamber diamond }\end{array}$ & $\begin{array}{l}3.2(2.1-6.4)^{\mathrm{a}} \\
37.5(35.0-42.7)\end{array}$ & $<0.001$ & $\begin{array}{l}1.8(1.2-2.5)^{\mathrm{a}} \\
43.0(37.8-45.3)\end{array}$ & $<0.001$ & $\begin{array}{l}2.6(2.0-4.9)^{a} \\
24.6(22.6-29.9)\end{array}$ & $<0.001$ & $\begin{array}{l}0.2(0.1-0.8)^{a} \\
20.5(19.2-25.7)\end{array}$ & $<0.001$ \\
\hline $\begin{array}{l}\text { Babyhaler } \\
\text { Vortex }\end{array}$ & $\begin{array}{l}3.2(2.1-6.4)^{\mathrm{a}} \\
46.9(42.6-51.0)\end{array}$ & $<0.001$ & $\begin{array}{l}1.8(1.2-2.5)^{\mathrm{a}} \\
3.1(1.2-3.8)^{\mathrm{a}}\end{array}$ & 0.200 & $\begin{array}{l}2.6(2.0-4.9)^{a} \\
21.1(20.9-23.0)\end{array}$ & $<0.001$ & $\begin{array}{l}0.2(0.1-0.8)^{\mathrm{a}} \\
2.0(1.6-2.3)^{\mathrm{a}}\end{array}$ & $<0.001$ \\
\hline $\begin{array}{l}\text { Optichamber diamond } \\
\text { Vortex }\end{array}$ & $\begin{array}{l}37.5(35.0-42.7) \\
46.9(42.6-51.0)\end{array}$ & $<0.001$ & $\begin{array}{l}43.0(37.8-45.3) \\
3.1(1.2-3.8)^{\mathrm{a}}\end{array}$ & $<0.001$ & $\begin{array}{l}24.6(22.6-29.9) \\
21.1(20.9-23.0)\end{array}$ & 0.004 & $\begin{array}{l}20.5(19.2-25.7) \\
2.0(1.6-2.3)^{a}\end{array}$ & $<0.001$ \\
\hline
\end{tabular}

Values in bold = VHC with statistically significantly higher drug delivery in the pairwise comparison. P-values, Mann-Whitney U test.

aSome values are below the limit of quantification (LOQ). 